\title{
07;12
}

\section{Экспериментальное моделирование алмазной бета-вольтаической батареи}

\author{
(C) В.Н. Амосов ${ }^{1}$, В.Н. Бабичев ${ }^{1}$, Н.А. Дятко ${ }^{1}$, С.А. Мещанинов ${ }^{1}$, \\ А.Ф. Паль ${ }^{1,2, \uparrow, ~ Н . Б . ~ Р о д и о н о в ~}{ }^{1}$, А.Н. Рябинкин ${ }^{1,2}$, \\ А.Н. Старостин ${ }^{1}$, А.В. Филиппов ${ }^{1}$ \\ ${ }^{1}$ ГНЦ РФ Троицкий институт инновационных и термоядерных \\ исследований, Троицк, Москва, Россия \\ ${ }^{2}$ Научно-исследовательский институт ядерной фризики \\ им. Д.В. Скобельцына \\ Московского государственного университета им. М.В. Ломоносова, \\ Москва, Россия \\ ฯE-mail: apal@mics.msu.su \\ Поступило в Редакцию 14 марта 2018 г.
}

Изготовлены алмазные монокристаллические ті р-структуры (metal-intrinsic diamond-p-doped diamond) с барьером Шоттки на основе НТНР $p$-алмаза и $\mathrm{CVD} i$-алмаза размером $3 \times 3$ и $4.1 \times 4.28 \mathrm{~mm}$. C помощью широкоапертурного электронного пучка с начальной энергией $110 \mathrm{keV}$, частично рассеянного на пути к преобразователю слоями алюминия толщиной $14 \mu \mathrm{m}$ и воздуха $17 \mathrm{~mm}$, исследованы бета-вольтаические характеристики алмазных структур. Максимальная генерируемая мощность достигала $2.18 \mathrm{~mW}\left(41 \mathrm{~mW} / \mathrm{cm}^{2}\right)$ с КПД преобразования $2-3 \%$.

DOI: $10.21883 /$ PJTF.2018.15.46446.17290

Радиоизотопные батареи представляют большой интерес в качестве долговременных источников электрической энергии, способных работать в опасных и труднодоступных условиях без обслуживания. В зависимости от сорта изотопа и конструкции преобразователя, необходимого для конкретного применения, используются различные методы преобразования энергии ядерного распада в электричество [1]. Один из методов, основанный на генерации неравновесных носителей заряда в полупроводниковых структурах при их облучении $\beta$-излучением радиоактивного источника, позволяет осуществить прямое преобразование ядерной энергии в электричество. По сути, этот метод аналогичен фотовольтаическому методу, используемому в солнечных элементах. Соот- 
ветственно преобразователь $\beta$-излучения радиоактивного источника в электричество называется $\beta$-вольтаическим [2]. В настоящее время в качестве источника во многих работах рассматривается $\beta$-изотоп $\mathrm{Ni}-63$, а наиболее распространенным материалом преобразователя является кремний. Главные недостатки преобразователей на основе кремния невысокий коэффициент полезного действия (КПД) и проблемы с деградацией полупроводниковых структур вследствие радиационных повреждений.

Ранее было показано, что при использовании широкозонных непрямозонных полупроводников КПД $\beta$-вольтаического преобразователя повышается с увеличением ширины запрещенной зоны и может достигнуть 30\% для алмаза [3]. Дополнительное преимущество широкозонных полупроводников - их высокая радиационная стойкость. С появлением доступных широкозонных материалов начались эксперименты по разработке $\beta$-вольтаических преобразователей на их основе, например, с использованием $4 \mathrm{H}-\mathrm{SiC}$ [4] или $\mathrm{GaN}$ [5]. Однако наиболее перспективным материалом с точки зрения ширины запрещенной зоны, радиационной стойкости и других уникальных характеристик является алмаз [6]. До недавнего времени применение алмаза для преобразования энергии было ограничено из-за отсутствия доступной технологии получения качественных монокристаллических алмазных материалов, но теперь в этой области наблюдается существенный прогресс. Хорошо разработаны методы получения монокристаллического HTHP (high temperature-high pressure) и CVD (chemical vapour deposition) алмаза большого размера [7].

Поскольку существуют принципиальные затруднения при изготовлении и применении легированных $p-n$-алмазных структур, в качестве преобразователей широко используются более доступные легированные бором алмазные структуры с барьером Шоттки $[8,9]$. На основе таких структур был изготовлен прототип ядерной батареи, содержащий 130 алмазных диодов Шоттки общей площадью $15 \mathrm{~cm}^{2}$ [6]. В этом устройстве под действием источника ${ }^{63} \mathrm{Ni}$ с активностью $5 \mathrm{mCi} / \mathrm{cm}^{2}$ получена плотность мощности $3 \mathrm{nW} / \mathrm{cm}^{2}$ при КПД $0.6 \%$. КПД батареи с источниками ${ }^{147} \mathrm{Pm}$ и ${ }^{90} \mathrm{Sr}$ составил 1 и $0.004 \%$ соответственно.

Масштабные экспериментальные исследования преобразователей с радиоизотопными источниками тормозятся высокой стоимостью обогащенных изотопов и трудностями их сопряжения с преобразователем. Поэтому для экспериментального моделирования работы такого конвер-

Письма в ЖТФ, 2018, том 44, вып. 15 
тора в качестве источника электронов часто применяется сканирующий электронный микроскоп (СЭМ) [6,9,10]. Однако использование электронного микроскопа для симуляции радиоизотопного источника имеет очевидный недостаток: он генерирует моноэнергетический пучок электронов достаточно малого диаметра. Такой пучок не может адекватно моделировать реальный энергетический спектр и угловое распределение электронов, вылетающих из слоя радиоизотопа [11]. В упомянутых выше работах $[6,9]$ электронный пучок СЭМ диаметром $0.5 \mu \mathrm{m}$ был направлен перпендикулярно преобразователю, что, вероятно, могло привести к завышенным значениям КПД преобразования алмазного диода Шоттки: 6 [6] и 9.4\% [9]. Методика прогнозирования характеристик ${ }^{63} \mathrm{Ni}$-батареи на основе моделирования транспорта электронов (методом Монте-Карло) и генерации избыточных носителей тока в полупроводнике совместно с измерениями параметров преобразователя с помощью СЭМ предложена в $[11,12]$.

Целью настоящей работы является экспериментальное исследование $\beta$-вольтаического эффекта в алмазных структурах, аналогичных рассмотренным в $[8,9]$, с помощью широкоапертурного электронного пучка, рассеянного на пути к преобразователю алюминиевой фольгой и воздухом. Меняя напряжение на пушке, толщину и материал фольги, а также расстояние до преобразователя, можно превратить моноэнергетический электронный пучок в поток электронов с распределением по энергии и углу, близким к распределению излучения конкретного $\beta$-активного изотопа. Использование дополнительной фольги вблизи входной диафрагмы преобразователя позволит получить угловое распределение электронов, приближающееся к изотропному.

В наших экспериментах в качестве $\beta$-вольтаического преобразователя использовались алмазные тір-структуры (metal-intrinsic diamond-p-doped diamond) на подложках из синтетического НТНРалмаза типа IIb c концентрацией бора $10^{18} \mathrm{~cm}^{-3}$. На подложки наносились эпитаксиальные алмазные пленки CVD типа IIa в условиях, аналогичных приведенным в $[6,8]$. Были изготовлены два преобразователя: В3 размером $3 \times 3 \mathrm{~mm}$ с толщиной подложки $300 \mu \mathrm{m}$, толщиной пленки $10 \mu \mathrm{m}$, контактами из платины толщиной $40 \mathrm{~nm}$, с задним сплошным электродом и входным в виде сетки с шагом $100 \mu \mathrm{m} ; \mathrm{Br} 03$ с подложкой размером $4.1 \times 4.28 \mathrm{~mm}$ и толщиной $500 \mu \mathrm{m}$, толщиной пленки $40 \mu \mathrm{m}$, сплошными алюминиевыми контактами толщиной $40 \mathrm{~nm}$. Подложка образца $\mathrm{Br} 03$ подвергалась высокотемпературному отжигу

Письма в ЖТФ, 2018, том 44, вып. 15 


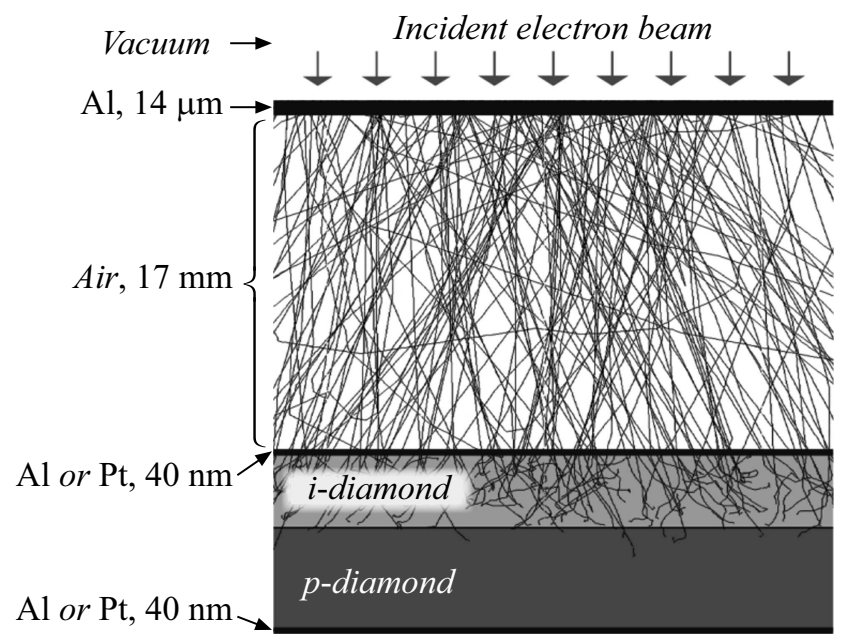

Рис. 1. Схема эксперимента. Линиями показаны траектории электронов.

в диапазоне от 1000 до $1500^{\circ} \mathrm{C}$ с интервалом $100^{\circ} \mathrm{C}$ и травлению в кислородной среде с последующим эпитаксиальным ростом. На обоих преобразователях была установлена входная диафрагма диаметром $2.6 \mathrm{~mm}$.

Для имитации $\beta$-источника использовалась электронная пушка с размером выходного окна $12 \times 20 \mathrm{~mm}$. Моноэнергетический пучок электронов с энергией до $110 \mathrm{keV}$ и плотностью тока до $1000 \mu \mathrm{A} / \mathrm{cm}^{2}$ инжектировался из вакуумного объема пушки в атмосферу через алюминиевую фольгу толщиной $14 \mu \mathrm{m}$. Помещенный в стандартный коаксиальный корпус $\beta$-вольтаический преобразователь располагался на расстоянии $17 \mathrm{~mm}$ от фольги. Пучок электронов на пути к преобразователю рассеивался в алюминиевой фольге и воздухе, плотность тока уменьшалась при этом, согласно расчетам, на три порядка. Ток пучка, проходящего через диафрагму преобразователя, измерялся непосредственно с помощью цилиндра Фарадея.

Принципиальная схема эксперимента с указанием основных конструктивных элементов преобразователя показана на рис. 1. На рис. 2 приведены вольт-амперные характеристики (BAX) преобразователей В3

Письма в ЖТФ, 2018, том 44, вып. 15 

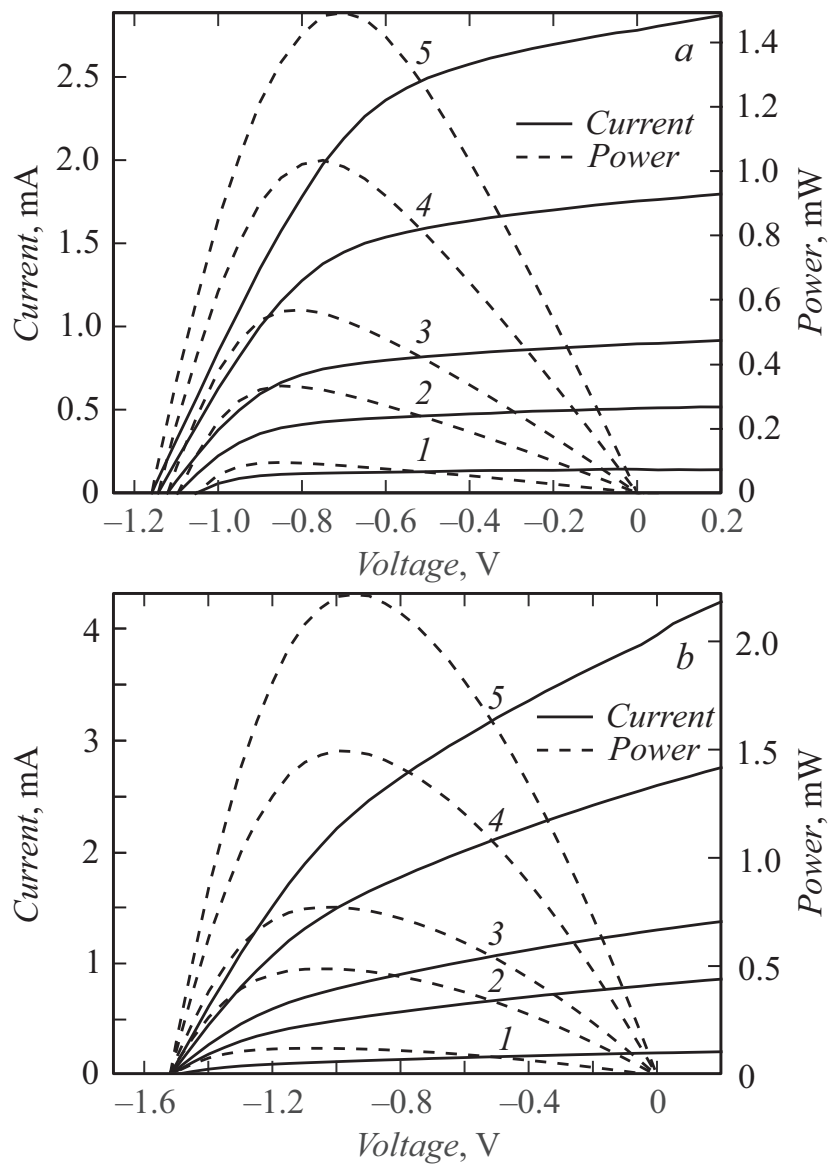

Pис. 2. BAX и зависимости мощности от напряжения для детекторов $\mathrm{B} 3$ (a) и $\operatorname{Br} 03(b)$ при средней энергии пучка $87 \mathrm{keV}$. Ток пучка, $\mu \mathrm{A}: 1-0.052,2-0.17$, $3-0.27,4-0.57,5-0.81$.

и $\mathrm{Br} 03$ при фиксированном напряжении электронной пушки $(110 \mathrm{kV})$ и различных токах электронов, а на рис. 3 - зависимости КПД преобразования от тока электронов при напряжении на пушке $110 \mathrm{kV}$. Чтобы оценить энергетический спектр и угловое распределение элек-

7 Письма в ЖТФ, 2018, том 44, вып. 15 


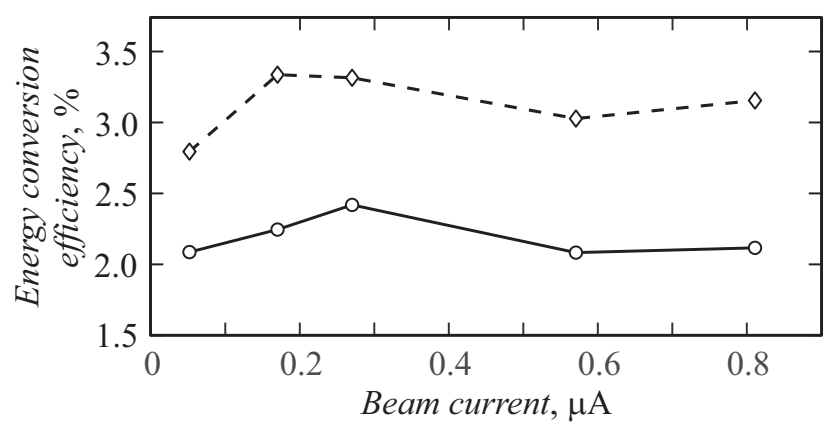

Рис. 3. Зависимости КПД преобразования от тока при средней энергии электронов $87 \mathrm{keV}$. Сплошная линия - преобразователь Br03, штриховая B3.

тронов, попадающих во входную диафрагму преобразователя, были выполнены расчеты прохождения электронов через фольгу и воздушный промежуток методом Монте-Карло. Метод расчета описан, например, в [13]. Электроны запускались по всей площади выходного окна пушки, а регистрировались характеристики тех из них, которые попадали во входную диафрагму. Согласно расчетам, при напряжении на пушке $110 \mathrm{kV}$ средняя энергия электронов, попадающих в преобразователь, составляла $87 \mathrm{keV}$, а средний угол - $15-20^{\circ}$.

Эксперименты показали, что КПД преобразования энергии электронов, проходящих входную диафрагму, составляет 2-3\%, максимальная полученная электрическая мощность равна $2.18 \mathrm{~mW}$ (удельная мощность на единицу площади преобразователя $\left.41 \mathrm{~mW} / \mathrm{cm}^{2}\right)$, фактор заполнения ВАХ меняется в диапазоне 0.46-0.65 и 0.37-0.5 для преобразователей В3 и Br03 соответственно. Специальные эксперименты показали, что тормозное излучение электронов пучка, поглощенных корпусом преобразователя, вносит пренебрежимо малый вклад в вырабатываемую мощность алмазного преобразователя.

Таким образом, в настоящей работе предложен и успешно продемонстрирован экспериментальный метод моделирования процесса $\beta$-вольтаического преобразования энергии, а испытанные алмазные структуры показали возможность генерации электрической мощности в десятки $\mathrm{mW} / \mathrm{cm}^{2}$. 
Работа выполнена при финансовой поддержке РНФ (проект № 16-12-10511).

\section{Список литературы}

[1] Prelas M.A., Weaver C.L., Watermann M.L., Lukosi E.D., Schott R.J., Wisniewski D.A. // Prog. Nucl. Energy. 2014. V. 75. P. 117-148.

[2] Olsen L.C., Cabauy P., Elkind B.J. // Phys. Today. 2012. V. 65. P. 35-38.

[3] Olsen L.C. Review of betavoltaic energy conversion // Proc. of the 12th Space Photovoltaic Research and Technology Conf. Washington, 1993. P. 256-267.

[4] Thomas C., Portnoff S., Spencer M.G. // Appl. Phys. Lett. 2016. V. 108. P. 013505.

[5] Voss P.L., Ougazzaden A. // J. Appl. Phys. 2015. V. 118. P. 105101.

[6] Bormashov V., Troschiev S., Volkov A., Tarelkin S., Korostylev E., Golovanov A., Kuznetsov M., Teteruk D., Kornilov N., Terentiev S., Buga S., Blank V. // Phys. Status Solidi A. 2015. V. 212. P. 2539-2547.

[7] Хмельницкий Р.А. // УФН. 2015. Т. 182. № 2. С. 143-159.

[8] Tarelkin S., Bormashov V., Korostylev E., Troschiev S., Teteruk D., Golovanov A., Volkov A., Kornilov N., Kuznetsov M., Prikhodko D., Buga S. // Phys. Status Solidi A. 2016. V. 213. P. 2492-2497.

[9] Delfaure C., Pomorski M., Sanoit J. // Appl. Phys. Lett. 2016. V. 108. P. 252105.

[10] Chandrashekhar M.V.S., Thomas C.I., Li H., Spencer M.G., Lal A. // Appl. Phys. Lett. 2006. V. 88. P. 033506.

[11] Polikarpov M.A., Yakimov E.B. // Solid State Phenom. 2016. V. 242. P. 312-315.

[12] Yakimov E.B. // Appl. Rad. Isotop. 2016. V. 112. P. 98-102.

[13] Гурашвили В.А., Джсигайло И.Д., Дятко Н.А., Занозина Е.М., Кочетов И.В., Спищын Д.И., Ткаченко Д.Ю. // Физика плазмы. 2012. Т. 38. № 1. C. $52-57$.

7* Письма в ЖТФ, 2018, том 44, вып. 15 